\title{
O TRABALHO DO PSICÓLOGO NA COMUNIDADE: UM RELATO DE EXPERIÊNCIA
}

The work of the psychologist in the community: a report of experience

\section{Kairon Pereira de Araújo Sousa ${ }^{1}$}

RESUMO: Este artigo tem como objetivo expor um relato de experiência no campo da psicologia comunitária, servindo para contribuir com as discussões sobre o fazer do psicólogo na comunidade. Para tanto, serão apontados os trabalhos que realizamos em uma comunidade na cidade de Floriano-PI durante o mês de novembro a dezembro de 2011.

PALAVRAS-CHAVE: Comunidade, Psicologia Comunitária, Relato de Experiência.

ABSTRACT: This article aims to present an account of experience in the field of community psychology, serving to contribute to the discussions about the psychologist's doing in the community. To do so, we will highlight the work that we have done in a community in the city of Floriano-PI during the month of November to December 2011.

KEY WORDS: Community, Psychology, Experience Report.

\section{INTRODUÇÃO}

A psicologia comunitária, no Brasil, tem como contexto o período marcado pela ditadura militar. Com a oficialização da psicologia como profissão por volta do ano de 1962, pouco tempo antes da instalação do regime militar propriamente dito, a psicologia, nessa fase, tem sua prática voltada para um atendimento individual, mantendo o status da ideologia dominante, sendo caracterizada como uma práxis elitista. Como destaca Scarparo e Guareschi (2007, p.100), “na época, as práticas psicológicas se consolidaram sob a influência de ideologias desenvolvimentistas [...]". Nesse sentido, como ainda apontam as autoras, "o trabalho do psicólogo era definido a partir da clínica individual, da tarefa de avaliação psicológica e do acompanhamento de dificuldades de aprendizagem nas escolas" (SCARPARO; GUARESCHI, 2007, p.100).

Como se pode notar, o fazer psicologia, nesse contexto, atendia as necessidades estabelecidas pelo regime, através de uma atuação tradicional baseada no modelo da clínica médica, cujo foco era o atendimento individualizado, desconectado do contexto sociocultural. Senso assim, as reflexões acadêmicas acerca do social eram muito restritas. Somente por volta da

\footnotetext{
${ }^{1}$ Bacharel em psicologia (UESPI), com especialização em saúde da família (CEAD/UFPI).
} 
década de setenta, começam a surgir às primeiras intervenções da psicologia abrangendo o contexto comunitário. Segundo Scarparo e Guareschi (2007, p.101):

Tais registros referiram-se à participação de psicólogos em trabalhos associados à esfera da educação e da saúde mental, especialmente no âmbito da prevenção. As ações eram inspiradas na psiquiatria comunitária, um ramo da psiquiatria social voltado para o atendimento à saúde mental de integrantes de comunidades.

Com o enfraquecimento do movimento militar e mobilização da população pelo fim da repressão, no cenário da psicologia, também surgiram manifestações de intelectuais que buscavam repesar a forma de se fazer psicologia, questionando sua atuação centralizada, que se ausentava das responsabilidades sociais. Conforme refere Campos (1996, p.17), "esta preocupação é mais sentida na universidade, quando a partir do movimento de 1968, questionando o ensino e a academia, é desenvolvida uma reflexão crítica sobre seu papel”.

Dessa maneira, a psicologia comunitária, como verifica Ornelas (1997, p.375), surge “[...] no decurso de um período de grandes transformações, não somente na área da Saúde Mental, mas também na sociedade em geral". Assim, tomando como base os conhecimentos da psicologia social, "a Psicologia Comunitária dedica-se a estudar, compreender e intervir no cenário de questões psicossociais que caracterizam uma comunidade" (SCARPARO; GUARESCHI, 2007, p. 103).

A psicologia comunitária pode ser definida, como aponta Góis (1993 apud CAMPOS, 1996, p.11) como:

uma área da psicologia social que estuda a atividade do psiquismo decorrente do modo de vida do lugar/comunidade, estuda o sistema de relações e representações, identidade, níveis de consciência, identificação e pertinência dos indivíduos ao lugar/comunidade e aos grupos comunitários [...].

O trabalho do psicólogo comunitário em uma comunidade visa sobremaneira à formação de uma consciência crítica da própria população, que nesse processo, participa de forma ativa na identificação e na resolução de suas necessidades principais. Campos (1996, p.10) destaca que:

\footnotetext{
tipicamente os trabalhos comunitários partem de um levantamento das necessidades e carências vividas pelo grupo-cliente [...]. A seguir, utilizando-se métodos e processo de conscientização, procura-se trabalhar com os grupos populares para que eles assumam progressivamente seu papel de sujeitos de sua própria história, conscientes dos determinantes sócio-políticos de sua situação e ativos na busca de soluções para os problemas enfrentados.
}

Com base nesse exposto, o presente trabalho descreve todas as etapas da atividade de extensão desenvolvida, no campo da psicologia comunitária, em uma comunidade residente no final da Rua 7 de Setembro, bairro São Cristóvão, na cidade de Floriano-PI, durante o mês de 
novembro e dezembro de 2011. Para tanto, iniciaremos apontando a descrição do local de intervenção (localização, histórico do local), e logo em seguida as atividades desenvolvidas (contato inicial: apresentação à comunidade; levantamento das necessidades; discussão das problemáticas do local- apresentação de sugestões; encontros seguinte - Ação - identificação de novas demandas; realização de dinâmica; último encontro).

\section{DESCRIÇÃO DO LOCAL DA INTERVENÇÃO}

\subsection{Localização:}

A comunidade, na qual foi realizado o trabalho está situada na Rua 7 de Setembro, no bairro São Cristovão, Floriano- PI, CEP: 64800-000, tendo como ponto de referência o pesquepague. É um trecho final dessa rua, composto pelo total de 20 casas.

\subsection{Histórico do local}

Esse bloco de casas, no final da Rua 7 de Setembro, começou a ser construído por volta de abril de 2010, por uma empresa de construções, que comprou a área de cerca de 150 metros, construindo inicialmente duas casas que serviram de base para a construção das demais. As primeiras casas foram entregues no mês de novembro do mesmo ano. As outras foram concluídas no começo da primeira metade de 2011. A venda dessas residências foi efetuada em parceria com a Caixa Econômica Federal, através do Programa Minha Casa Minha Vida. São casas compostas pelo total de 7 cômodos, algumas com cômodos a menos, devido modificações realizadas a pedido dos moradores. Além disso, possuem quinta e um espaço para um jardim.

Por ser uma comunidade nova, não dispunha ainda de calçamento e iluminação pública.

\section{ATIVIDADES DESENVOLVIDAS}

Foram desenvolvidas atividades variadas nessa comunidade. Para tanto, partimos de uma observação sobre o local de estágio. Procuramos conhecer um pouco da história desse lugar: como surgiu a comunidade? Quantas famílias moram na mesma? Nesse sentido, conversamos, com um dos moradores que há onze anos vive na região, e a partir das informações fornecidas por ele, tivemos uma visão mais detalhada da comunidade. Como se tratava de uma parte nova, formada ao todo por 20 casas, foi por meio do morador que obtivemos acesso aos demais. Assim, a primeira etapa desse trabalho consistiu em uma análise do lugar. Posteriormente, fomos dando início aos trabalhos com encontros periódicos que variavam em decorrência das ocupações dos moradores e, como forma de mantermos os encontros, fomos adaptando as reuniões de acordo com as necessidades do coletivo. 


\subsection{Contato inicial: apresentação a comunidade}

Nosso primeiro encontro ocorreu no dia 12 de novembro de 2011, às 14 horas da tarde, sendo realizado na casa de um dos moradores da comunidade, tendo 09 participantes, com duração de 1 hora e 30 min. Iniciamos a atividade nos apresentando ao grupo e pedindo a eles que também se apresentassem, como forma de gerar interação entre os participantes. Logo após falamos um pouco sobre nossos objetivos em relação à comunidade, explicando do que se trata a psicologia comunitária e como funcionaria as ações desenvolvidas com eles. Expomos um pequeno vídeo (7 min) da própria comunidade, fazendo um resgate da história do lugar. Também apresentamos outro vídeo ( $7 \mathrm{~min})$ com o tema "O problema não é meu", produção American Media, que apesar de ser em forma de desenho animado, continha uma mensagem muito rica para o propósito da atividade. Esse vídeo mostrava uma comunidade que tinha um problema, representado por um pequeno fogo que começou após alguém atirar um instrumento com fogo no mato que cercava a comunidade (uma organização). As pessoas viram o problema, mas ninguém tomava a iniciativa de solucioná-lo, desse modo, o problema foi crescendo, enquanto um e outro de afastava da responsabilidade. Finalmente, quando o fogo já estava para destruir a comunidade, enquanto eles brigavam entre si a respeito de quem deveria ou era o responsável por solucionar a dificuldade, um cachorrinho solta um assobio e mostra a eles um cartaz "assuma sua responsabilidade". Nesse momento, pararam e perceberam que o problema era de todos e que somente cada um fazendo sua parte, assumindo a sua responsabilidade, poderiam juntos solucionar o problema e assim o fizeram.

Foi a partir dessa temática "assuma sua responsabilidade", que refletimos com os moradores a respeito da função de cada um na comunidade, ou seja, que eles são agentes transformadores da realidade do lugar em que vivem. Em seguida, iniciamos a discussão das necessidades da comunidade.

\subsection{Levantamento das necessidades}

Percebemos durante as discussões o entusiasmo dos moradores que foram expondo seus pontos de vista a cerca das problemáticas do lugar. Deixamo-los à vontade para discutirem essas necessidades, fazendo intervenções apenas quando necessário. Às vezes, fazíamos feedback utilizando o vídeo.

Nesse momento de levantamento das necessidades da comunidade, eles apontaram como problemas a serem trabalhados: o calçamento da rua, a iluminação (problema com uma das lâmpadas dos postes), o lixo (logo ao lado da comunidade, caminhos despejam lixo em um 
terreno, o que gera mau cheiro e atraia animais, até mesmo mosquito da dengue), presença de mato ao redor das casas (que serve de esconderijo para animais) e a circulação de caminhões carregados de areia, de uma empresa, que danificava ainda mais a rua, além da possível instalação de um depósito dessa mesma firma próximo às casas, que com o peso dos caminhões que passariam mais próximo das residências, colocaria a estrutura das mesmas em risco. Algumas das casas, segundo os moradores, com a circulação diária de caminhões e tratores, estavam com rachaduras nas paredes.

\subsection{Discussão das problemáticas do local - apresentação de sugestões}

Ainda no primeiro encontro, discutimos com os moradores planos estratégicos para a solução das demandas destacadas. Utilizando o vídeo anterior, demonstramos que a identificação de um problema não costuma ser difícil (como verificado no filme), porém, precisaríamos, já que foram mencionadas as dificuldades, que agora eles formulassem possíveis respostas ao problema.

A comunidade começou a buscar os meios para vencer suas problemáticas. Verificamos que essa parte foi a mais difícil. Perguntamos a eles se tinham compreendido o que estávamos pedindo. E, para ajudarmos voltamos a utilizar cenas do vídeo, explicando como a comunidade mencionada no filme fez para contornar sua problemática.

Feito o esclarecimento, diversas opiniões começaram a surgir, e a própria comunidade foi fazendo, a partir da análise dos prós e contras, a seleção dos meios mais precisos de se atingir os resultados almejados. O quadro abaixo contém as estratégias elaboradas:

Tabela 1 - Estratégias elencadas como forma de solucionar os dilemas da comunidade.

\begin{tabular}{c|l}
\hline PROBLEMA & \multicolumn{1}{c}{ SOLUÇÃO } \\
\hline Calçamento & $\begin{array}{l}\text { Comunicar às autoridades acerca das } \\
\text { dificuldades que os moradores atravessam } \\
\text { (poeira, lama, etc.) devido a falta de calçamento. } \\
\text { Solicitar a pavimentação da rua. }\end{array}$ \\
\hline Lixo & $\begin{array}{l}\text { Pedir à prefeitura que tome providências em } \\
\text { relação ao despejo incorreto de lixo naquele } \\
\text { lugar. Fiscalização pelos moradores para não } \\
\text { deixar que outras pessoas depositem lixo no } \\
\text { local. }\end{array}$ \\
\hline Iluminação & $\begin{array}{l}\text { Como apenas um dos postes, há alguns meses, } \\
\text { estava com a lâmpada queimada e a prefeitura } \\
\text { havia informado aos moradores que estava } \\
\text { aguardando a chegada de várias lâmpadas com }\end{array}$ \\
\hline
\end{tabular}




\begin{tabular}{|c|c|}
\hline & $\begin{array}{l}\text { outros equipamentos para fazer a troca em toda } \\
\text { a cidade. Os moradores das quatro primeiras } \\
\text { casas, que são os mais prejudicados com a falta } \\
\text { da iluminação desse poste, decidiram comprar a } \\
\text { lâmpada juntos e pedir à prefeitura que } \\
\text { realizasse a instalação. }\end{array}$ \\
\hline Mato em frente às casas & $\begin{array}{l}\text { O mato em frente às residências, ao mesmo } \\
\text { tempo em que era um problema individual (de } \\
\text { cada morador), também se tornava coletivo, } \\
\text { porque, nele se escondiam vários animais } \\
\text { (mosquitos, sapos, aranhas, etc.), representando } \\
\text { um perigo aos moradores. Dessa forma, eles } \\
\text { decidiram que cada um faria a limpeza de sua } \\
\text { área, tendo assim no final um resultado } \\
\text { coletivo. }\end{array}$ \\
\hline $\begin{array}{c}\text { Circulação de veículos pesados com } \\
\text { danificação da rua }\end{array}$ & $\begin{array}{l}\text { Como na comunidade, diariamente passam } \\
\text { caminhões carregados de área subtraída do rio, } \\
\text { prejudicando ainda mais a rua (em função do } \\
\text { peso desses veículos, várias vezes o cano de } \\
\text { água foi quebrado, deixando os moradores } \\
\text { prejudicados). Foi sugerida uma conversa com } \\
\text { o proprietário dos veículos para que ele } \\
\text { utilizasse sua frota e no final de semana } \\
\text { tampasse os buracos, fazendo o planeamento. }\end{array}$ \\
\hline
\end{tabular}

Fonte - Arquivo pessoal.

\subsection{Encontros seguintes:}

\subsubsection{Ação}

No segundo encontro (19/11/2011/ às 14 horas) revisamos com os moradores, agora em um número maior, as atividades desenvolvidas na reunião anterior. Depois, pedimos para eles que relatassem o que a comunidade havia realizado tendo como base as estratégias elaboradas.

Em relação à iluminação, os moradores próximos ao poste com a lâmpada queimada, não precisaram comprá-la, porque, o secretário de infraestrutura da prefeitura enviou uma equipe de funcionários para fazer a instalação.

No caso do lixo, a prefeitura executou a limpeza do lugar, afastando o lixo próximo às residências, colocando uma placa com o aviso "proibido jogar lixo". 
A respeito do mato, cada morador fez a limpeza da frente da casa, deixando a área mais limpa.

Quanto à circulação dos veículos, o proprietário cooperou com a comunidade tampando os buracos da rua.

Continuamos o encontro fazendo a exposição de uma minipalestra sobre o lixo depositado em lugares incorretos. Finalizamos com um vídeo que mostrava a superação das dificultadas em conjunto (trechos do filme: Desafiando Gigantes).

\subsubsection{Identificação de novas demandas}

Nesse encontro (26/11/2011/ às 15 horas), iniciamos com o feedback sobre o vídeo anterior e discutimos com a comunidade novas demandas que porventura eles queriam trabalhar. Foi mencionada a possibilidade de a comunidade buscar o saneamento básico, uma vez que o esgoto das casas não tem por onde escorrer. Além, da questão de normalizar o serviço de coleta do lixo, que no início passava duas vezes por semana no lugar (terças e quintas), entretanto, há alguns dias o carro do lixo estava passando apenas durante as terças e sábados (um prazo muito extenso que gerava acumulação de lixo).

Diante desse exposto, pedimos a eles que novamente tentassem formular solução para essa nova problemática.

Terminamos o encontro, com a proposta dos moradores de procurarem os responsáveis pela limpeza e solicitarem a disponibilização do serviço durante os dias da semana propostos por eles.

\subsubsection{Realização de dinâmica}

No quarto encontro (3/12/2011/ às 17 horas), realizamos uma dinâmica com os moradores. Dividimo-los em duas equipes, e pedimos que utilizando os materiais fornecidos (cartolina, cola, lápis de cor e tesoura), tentassem montar um castelo em tempo mínimo, tendo no máximo 10 minutos para concluir a tarefa. Cada grupo recebeu material, porém, um dos grupos recebeu cartolina, lápis de cor e tesoura, enquanto o outro, cartolina, cola e lápis de cor. O objetivo da tarefa era fazer com que ao perceberem a falta de determinado instrumento, que o outro grupo dispunha, eles, de modo a concluir a tarefa, cooperassem entre si, fornecendo um ao outro o instrumento que estava faltando.

Após a realização da dinâmica, realizamos o feedback, mostrando novamente a importância de se trabalhar em grupo, destacando aspectos importantes, como a liderança, o trabalho 
colaborativos, etc. Falamos da possibilidade de convidar o secretário de infraestrutura para conversar com a comunidade.

\subsection{4 Último encontro}

Nosso último encontro com a comunidade (13/12/2011/ às 17 horas) foi marcado por uma conversa entre moradores e o secretário de infraestrutura do município, sobre algumas necessidades da comunidade. $\mathrm{O}$ assunto tratado foi à questão do calçamento.

Os moradores apontaram as dificuldades em relação à falta de calçamento na rua, e também sobre a questão do lixo e da ação da empresa que estava se instalando de forma inadequada na área, executando desmatamento de uma região de reserva florestal. Logo em seguida, o secretário, apresentou as propostas de intervenção, estipuladas pela secretária de infraestrutura do município.

Sobre o calçamento, afirmou que em reunião com o prefeito municipal, ficou estabelecido que essa região seria a primeira a receber o calçamento a partir do ano seguinte. Ele estabeleceu um prazo com a comunidade para terminar a obra (até junho de 2012), mas enquanto a pavimentação não era iniciada, o secretário se dispôs a enviar uma equipe com máquinas, para fazer o planeamento da rua, restaurando os buracos, além disso, comprometeu-se de entrar em contato com a secretária do meio-ambiente para denunciar o desmatamento ilegal, executado pela empresa na região. Em relação ao lixo, solicitou a participação dos moradores, para que ao verem algum veículo depositando lixo na área próxima às casas, anotassem a placa do veículo, informando as autoridades municipais, já que a prefeitura colocou um anúncio na área pedindo as pessoas para não jogarem lixo no lugar.

Depois de revisarmos todos os trabalhos desenvolvidos ao logo desses encontros com os moradores, apontando as conquistas que os mesmos tiveram durante o processo. Solicitamos a eles que fizessem um feedback sobre o trabalho realizado: o que esses encontros tiveram de positivo para a comunidade? $\mathrm{O}$ que gostariam que tivesse sido trabalhado e que não foi realizado durante nosso trabalho no lugar?

Depois de ouvi-los, finalizamos o trabalho agradecendo aos moradores pela colaboração e destacando que o trabalho iniciado poderia ser continuado pela comunidade, que nós apenas tivemos uma iniciativa, mas que eles agora como verificado no trabalho, são sujeitos ativos no desenvolvimento e conquistas de novos objetivos para a comunidade.

\section{CONCLUSÃO}


O trabalho de intervenção, na comunidade, ocorrido durante a disciplina de psicologia social-comunitária do curso de psicologia da UESPI, Campus de Floriano-PI, permitiu um contato mais próximo com o ambiente de atuação do profissional da psicologia comunitária (a comunidade). Momento em que foi possível estabelecer, não apenas uma postura crítica, mas também uma reflexão de como ocorre à prática profissional nesse setor da psicologia. Ao mesmo tempo, foi possível relacionar teoria e prática itens indispensáveis a uma formação mais sólida.

A realização desse trabalho na comunidade nos levou a um questionamento a respeito da própria ciência psicológica que se trata de uma área muito ampla, com diversas secções, e a psicologia comunitária surge como uma nova forma do fazer psicologia, e apesar de ser um setor novo, vem crescendo muito no país, sobretudo, com as novas formas de trabalho com as comunidades.

Ficamos deslumbrados por ter contribuído, através de intervenções baseadas nos conhecimentos da psicologia, com a construção de uma comunidade melhor, mostrando aos moradores desse local que eles mesmos poderiam trabalhar suas problemáticas, buscando soluções em conjunto. Dessa forma, acreditamos termos preparado a comunidade com instrumentos necessários para eles darem continuidade a esse processo, que não se esgota nessa intervenção que realizamos. Fomos apenas orientadores, mas não os responsáveis pelas transformações que ocorreram na comunidade. Assim, demonstramos para eles, desde o início, que somente os mesmos poderiam modificar a realidade em que estão inseridos.

Houve, portanto, uma reciprocidade, organizamos um trabalho com eles, orientando-os sobre como desenvolverem formas de atuação em prol da comunidade, e ao mesmo tempo eles nos forneceram a oportunidade de praticarmos, ou seja, de por em prática os conhecimentos que adquirimos na universidade.

\section{REFERÊNCIAS}

CAMPOS, R. H. F. Psicologia social comunitária: da solidariedade à autonomia. Petrópolis - RJ: Vozes, 1996.

DESAFIANDO GIGANTES. Produção Alex Kendrick. Estados unidos, Sherwood Pictures, 2006 (111 min).

$\mathrm{O}$

PROBLEMA

$\mathrm{NÃO}$

É MEU.

Disponível

em

http://www.youtube.com/watch?v=ORr3uyzz_Z8> Acesso em: 12 novembro. 2011.

ORNELAS, J. Psicologia comunitária Origens, fundamentos e áreas de intervenção. Análise

Psicológica, Lisboa, v.15, n.3, p.375-388, set. 1997. 
SCARPARO, H. B. K, GUARESCHI, N. M. F. Psicologia social comunitária e formação profissional. Psicologia \& Sociedade, Porto Alegre, v.19 n.2, p.100-108, 2007. 